\title{
On being bound to linguistic norms. Reply to Reinikainen and Kaluziński
}

\author{
Matthias Kiesselbach
}

\begin{abstract}
The question whether a constitutive linguistic norm can be prescriptive is central to the debate on the normativity of meaning. Recently, the author has attempted to defend an affirmative answer, pointing to how speakers sporadically invoke constitutive linguistic norms in the service of linguistic calibration. Such invocations are clearly prescriptive. However, they are only appropriate if the invoked norms are applicable to the addressed speaker. But that can only be the case if the speaker herself generally accepts them. This qualification has led critics to argue that if an addressed speaker's acceptance is a necessary condition for legitimate prescriptions (and reproach for failure to adhere to them), then the account becomes unable to underwrite actual normativity. Moreover, critics argue, a danger of vicious circularity arises from the calibration account. This paper shows that once a vantage point within the calibration practice is accepted, the criticisms lose their force. It then explores why a theorist might reject such a perspective and suggests, as a plausible candidate, implicit Humean assumptions about the proper explanation of (linguistic) action. The paper ends by sketching a way forward for the debate on the normativity of meaning in light of this diagnosis.
\end{abstract}

Key words: Normativity; Meaning; Linguistic Calibration; Humeanism

Acknowledgments: The author wishes to thank Giridhari Lal Pandit, Raja Rosenhagen and Sebastian Bünker for helpful comments on earlier drafts of this essay.

\section{Introduction}

Although it has been going on for some years now, the debate on the normativity of meaning does not show signs of a convergence, let alone approach any resolution. In this paper, I want to explore whether the barrier to mutually accepted dialectical progress might be the divergence on a particular set of methodological and substantial background assumptions which have, so far, escaped explication.

The occasion is presented by two recent articles (Kaluziński 2016, Reinikainen 2020) which criticize an attempt of mine (Kiesselbach 2014) to show that constitutive linguistic norms - norms constituting what is meant by a given sign or word - can be seen to be prescriptive once we turn our attention to the purpose or function of invoking them in linguistic practice.

The paper will start by sketching out my earlier argument and its attendant picture of norms (II). It will then present the anti-normativists' reactions and draw attention to 
their emphatic insistence that what is presented in the picture is nothing they can recognize as genuine normativity (III). After offering a defense of the account, it will address the question what background assumptions might be behind this reaction and suggest, as a plausible candidate, Humean intuitions about what can motivate action and a methodological attachment to a perspective from outside of the practice under investigation (IV). The hope is that the debate can move forward once these background commitments are (re-)considered in the context of the normativity of meaning. A sketch to this effect is presented in section $\underline{\mathrm{V}}$.

\section{Recap: a normativist proposal}

The point of departure of the debate's latest branch concerns the relationship between "constitutive" norms and "prescriptions". It may be true, anti-normativists concede, that linguistic conduct stands in "constitutive" relationships with meanings. But they insist that such relationships cannot yield "prescriptions" of any sort (Glüer 1999; Glüer and Pagin 1998; Hattiangadi 2006). Failing to use a word in accordance with rules that bind it, constitutively, to a particular meaning would just be to use it with a different or no meaning - not to "fail" in any deeper or more substantial sense. You can do something unanticipated, but you can't really do anything substantially wrong with your linguistic signs, anti-normativists insist. Or rather: if there is emphatic normative "wrongness", then that must be because of some implicit or explicit premise about etiquette, prudence, morals, desires, or some other non-semantic source of normativity.

Elsewhere I have tried to show, against the contentions of anti-normativists, that constitutive linguistic norms can be properly prescriptive, too (Kiesselbach 2014). The main point was that it is a mistake to read the normativity of meaning thesis as stating that the meaning of a given linguistic sign depends on the speaker conforming to the relevant constitutive linguistic norms. Rather, the meaning of the sign depends on these norms being applicable to the speaker in question (in the particular situation of utterance or inscription). Thus, contrary to the anti-normativist portrayal, a normativist can claim - and ought to claim, as I argue - that a speaker can fail to follow a linguistic norm and yet produce signs with the relevant meanings. A normviolation lays the speaker open to questioning and, depending on her answers, to justified rebuke - it does not necessarily endow her words with different meanings. The justified rebuke, moreover, is as indicative or expressive of normativity as it gets, and the latter can be properly said to have its roots in meaning as such.

Of course, this account provokes the question of what it is for linguistic norms to be applicable, and how such norms become applicable in the first place. In response to this anticipated question, I have sketched a picture of language use as a particular kind of score-keeping practice. My sketch is one of a practice in which agents normally exchange signs to change the "score" in mutually recognized and pre-ordained ways, but in which every now and then, there is a need to calibrate their diverging linguistic 
expectations and dispositions against one another. ${ }^{1}$ With their calibration manoeuvres, speakers explicitly address the connections among signs (and between signs and circumstances or actions) $)^{2}$ which, in more ordinary stretches of linguistic conduct, are drawn on to communicate about the world and our dealings in it. Agents can state their own view of such connections, they can ask others about theirs, and they can invite others to change their relevant dispositions, or change their own to cohere with those of their peers. The purpose of this sub-practice of calibration is, of course, to achieve continued smooth communication, including stable reference to the shared empirical world.

The suggestion is that when speakers enjoin each other, within these calibration practices, to speak in particular ways, they do so because they hold the respective constitutive norms to be applicable. To say "if you call this a 'dog', you ought to be prepared to call it an 'animal', too" is to give voice to a constitutive norm and to prescribe a particular linguistic conduct to another speaker. Notice that in the case of this sketched example, the tokens of the word "dog" uttered by the addressed speaker are taken to mean what they do - something which is an animal - even if the speaker has made a mistake in this regard. ${ }^{3}$ The same alignment between constitutivity and prescriptivity can be seen when someone says "I did not mean that by 'dog', I was not actually talking about live animals but stuffed toys", because such a statement can be read as an invitation to one's interlocutor to adapt her linguistic expectations and conduct to one's own, at least for the duration of the conversation or within the respective context. (A more explicit form of this manoeuvre could be: "I invite you to join me in using a relaxed concept of doghood in this conversation, with the following substitutional and practical roles...") From the perspective of the conversational norm whose institution is thus proposed, the statement both elucidates the norm (the meaning of a word within the proposed conversation, way of speaking, or context) and prescribes a particular linguistic conduct at the same time. ${ }^{4}$

The picture shows that norms are in force - and what it means for them to be in force - in language use and its sub-practice of calibration. And since the practice of linguistic calibration does not only serve to express existing norms but also to jointly institute them (when a proposal like the above one is taken up, for example), it also

\footnotetext{
${ }^{1}$ This emphasis sets my account of language as a score-keeping practice apart from that of Lewis (1979). It follows the spirit of Brandom (1994), although the latter does not explicitly discuss the practice of calibration as a sub-practice of language use.

2 Within the theoretical framework drawn on in my original paper, these are intra-linguistic (inferential, substitutional, anaphoric) as well as language entry- and exit rules (Sellars 1954, Brandom 1994), but the point can be taken over into other theoretical frameworks.

${ }^{3}$ At least initially and unless the speaker enters a clarification to the effect that she was using a different concept - more on this in the following paragraphs.

${ }^{4}$ It is even true when we say "oh, by 'cow' you mean to include water buffalo? Fine, let's call Daisy a cow" or "Well, if you insist, we'll call whale a kind of 'fish' (namely the kind with a lung)." These two affirmations are non-standard, and best interpreted as acceptances to institute novel breakaway practices. (More on this in the next section.) Whether it is wise to adapt one's own linguistic dispositions to such usages and thus allow the emergence of a breakaway practice is, of course, another matter.
} 
shows how they come into force - although, of course, it should be clear that there are other (implicit and traditional) ways for norms to come into force, too. ${ }^{5}$

I should admit that the picture sketched here highlights aspects of language use in ways that may not be theoretically neutral. In particular, the picture implicitly rejects views of language as constituted by a static, complex compendium of norms (like ice hockey or chess, say). In treating it, rather, as an overarching practice within which agents with only partially converging linguistic dispositions and expectations (making up overlapping idiolects, if you like) sporadically calibrate with each other, it allows that speakers sometimes bring forth new, local, joint norms which serve their purpose until they, too, are replaced in a new round of calibration. In this short piece, I cannot fully justify this set of assumptions ${ }^{6}$ beyond noting that it coheres well with everyday experience, that it is in line with influential theories of language, ${ }^{7}$ and that even if it were rejected as applicable to language use in its entirety, the sketch of our invocations of norms still shows how constitutivity can be compatible with prescriptivity.

Let me also stress that in making my case for the compatibility of constitutivity and prescriptivity of meaning-norms, I have taken a specific methodological decision. I have discussed the matter from the perspective of participants of linguistic practice and its sub-practice of linguistic calibration, and I have suggested that normative force arises from the doings of participants of the practice, and that it arises within the practice - for its agents, as it were. I have thus opted against an outsider or "sidewayson" perspective on normative linguistic practice, and I have relied on the readers' own familiarity with the practice in clearing up the misunderstanding about constitutivity. This turns out to be important, because rather than agreeing to take this vantage point, critics - upon noticing that the model invites a change of perspective along these lines - are tempted to employ it in a reductio against the approach. (The final sections of this paper will explore where the resistance to an internal perspective may have its roots.)

\section{Anti-normativist puzzlement: is this normativity?}

It is in reaction to my (slightly more formal than here) model of our calibration practice that the two recent papers have staged their attack. Both, in effect, ask how this practice is supposed to show anything that is recognizably normative. Kaluziński

\footnotetext{
5 Two recent articles which address (among other things) the stabilisation of meaning over time are Kompa (2019) and Enfield and Sidnell (2019). Notice, however, that according to the view presented here, conventions and/or coordination equilibria are not central to the elucidation of normativity.

${ }^{6}$ For more on this, see Kiesselbach $(2012,2014)$. The ideas sketched here are, of course, far from a complete account of meaning, at most a rough picture of its scaffolding. Among many important structural features not discussed are the various ways in which meanings can be determined externalistically. The only point I should register here is that these external determinations are built into our complex practice of mutual interpretation. See Kiesselbach $(2012,120 f$.) and especially Jackman (2005).

${ }^{7}$ Very roughly, I am speaking of the traditions downstream of Ludwig Wittgenstein, Wilfrid Sellars and Donald Davidson, instantiated, e.g., by Brandom (1994).
} 
asks "how Kiesselbach's account could be treated as an argument for the claim that meaning is prescriptive?" (Kaluziński 2016, 114) After all, he argues, if a speaker happens not to be disposed to call green things "green", then "there is no relevant normativity here-we just note that, in the first case, the semantic standards are met, and in the second case, they are not." Reinikainen, who displays the same puzzled reaction, makes it clear that he is missing the kind of normativity which we know from pro-attitudes (desires, inclinations, etc., see Reinikainen 2020). Reinikainen then tries to find a flaw in the model, and it is on this point that I want to focus on the next few pages.

Reinikainen starts by noting that according to my score-keeping model, in order for a speaker to be justified in treating another speaker as following a particular norm - as intending to use a word with a particular meaning -, the latter agent must have done something to bind herself to that norm and thus to allow others to hold her to it. I have put it as follows:

[ $] \mathrm{n}$ order to be appropriately assessed on the basis of a norm, one must have done something, have committed some sort of act of subjection - if not directed at the norm, then at the practice as such. (Kiesselbach 2014, 438)

I have called this a "broadly Kantian principle" (Kiesselbach 2014, 438) because of Kant's insistence that a "maxim" can only be binding for an agent if the agent has "bound herself" to it. Notice that the formulation allows for mistakes: one binds oneself to a norm as such, not (impossibly!) to an endless string of explicitly mentioned individual acts falling under it.

What, now, Reinikainen asks, is this something, and how can it make assessments of agents as bound to particular norms appropriate? The alleged inability of the model to say or show anything illuminating in response to these questions, it turns out, is the crux of his argument, and Reinikainen sees it in the background of Kaluziński's paper, too. Reinikainen first wonders whether the mentioned "act of subjection" Reinikainen himself speaks of "consent" - might consist in the having of a "nonnormative pro-attitude" towards the norm or the practice. I take this to be the kind of attitude which is studied by psychologists. He quickly puts this idea aside as that would mean that the actual source of the linguistic prescriptivity would be a psychological state, not a norm, thereby supporting an anti-normativist naturalism about meaning. I would add that this idea also elicits Kripkensteinian worries about how definite psychological states can underwrite norms which are, by their nature, indefinite, and register my own surprise that this worry seems not to carry much weight in the critics' opinion.

Reinikainen then turns to the possibility of characterizing this sometbing from the perspective of an agent within the normative practice. In this case, Reinikainen's charge is that such an attempt cannot avoid falling into a vicious circle. Before addressing the argument head-on, let me briefly dwell on a point which has both 
Reinikainen and Kaluziński worried and which lies in the immediate vicinity of the charge of vicious circularity: the fact that an agent who is reproached for having failed to follow a particular norm (for having misused a word) can claim that she had been following a different norm all along (had meant something else by it).

Suppose I say to you "if $y$ is a 'dog', then surely you can't call it a 'plant"' and you respond, "well, my concept of plant-hood is compatible with a dog being a plant". What do I do now? I could roll my eyes and treat you as meaning "living being" by "plant". It would be unusual to speak like that, but I just might be prepared to institute, jointly with you, a small, exclusive language game - just for you and me - in which "plant" can be substituted by "living being". (A similar fantasy is put on paper in Kiesselbach 2012.) If you then retort that some stones are "plants", too, and if I have no reason to treat you as superstitious or your statement as metaphoric, I could try to read your "plant" as interchangeable with "physical objects". Again, I might frown, but I may go along even with this way of speaking - until you treat numbers, laws and sonatas as "plants", too. In theory, this kind of exchange could go on forever. In reality, of course, I would probably give up on you and the hope that we may understand each other rather quickly.

Does this exchange show anything of interest? Well, yes: it affirms that the normativity of meaning has nothing to do with traditional or conventional language use. (I emphasized that in Kiesselbach 2014, too, as I did above.) We can always establish a non-traditional micro language-game - at the limit, between just two speakers - and then communicate and understand each other perfectly going forward. But it does not strike me as showing an actual problem for normativism. The latter is not committed to stating (absurdly) that break-downs in communication cannot happen, or that language is governed by one monolithic and static set of original rules, or that all participants to linguistic practice always act in good faith. In fact, normativists can and ought to - go the other way and openly admit that communicative break-downs are always possible, in fact frequent (at least in some areas of language use), and that interpretations of others as being committed to particular norms are therefore always provisional. Such interpretations are not thereby illegitimate, and Reinikainen's exclamation that "one can always declare to have assented to some other norms than [the one] which one is found violating" (Reinikainen 2020,12) simply strikes me as stating an obvious truth about what disingenuous agents can do in linguistic practice, ${ }^{8}$ rather than constituting a potent reductio against my account. Also Kaluziński's suggestion that if we have recourse to linguistic excuses, then "we do not need to follow semantic norms (at all)" (Kaluziński 2016, 114), suggesting that agents could legitimately make up excuse over excuse, strikes me as simply wrong.

This may be the right moment to insist that the "broadly Kantian principle" is actually motivated by an interpretive concern: interpreting an agent as following a norm, but as making sustained and wide-ranging mistakes in doing so, is interpretively unstable -

8 "Semantic gaslighting" might be an apt term for that. 
unless the agent can, at least in principle, be rationally convinced of her mistakes herself. If she cannot, and if there is also no causal story explaining her pattern of mistakes (colorblindness, perhaps?), then it is relatively more plausible that she was following a different norm, and we as interpreters are charged with finding out which norm this was. ' The "broadly Kantian principle" is not, as Reinikainen seems to think, meant to put a stop to (the danger of) some regress, or to insert a source of normativity into the overall theory. For this reason, my original paper was actually careful to state that an acknowledgement signal is not needed for a particular normative stance of the interpreter to be appropriate. ${ }^{10}$ And the principle is also not meant, as Kaluziński seems to think, to weaken the normative consequences of a theory feared to be too demanding. In the basic structure of mutual linguistic interpretation displayed in my linguistic score-keeping account, only norms accepted by an agent can be cited when issuing semantic reproach - but once a speaker's acceptance is established, the evaluating agent's reproach is as unyielding as it gets.

At any rate, the official argument of Reinikainen is that characterizing the "act of submission" from within normative practice leads to a vicious circle.

(1) Only someone who is part of the practice (has consented to it) can be appropriately assessed by the norms of the practice.

(2) Who is part of the practice is determined by assessment appropriate by the norms of the practice.

(3) So what counts as appropriately assessing someone as part of the practice is decided by assessment appropriate by the practice. (Reinikainen 2020, 13)

This "circularity" is, of course, related to the allegedly damaging regress - and dealt with in a similar way. But let me now give an explicit reply. What Reinikainen describes here (if I understand his complaint correctly) is not a vicious circularity in the theory (or explanation) but a structural feature of normative practice itself. Let me spell this out in three steps.

In a preliminary first step, let us agree that when a speaker is appropriately assessed as being part of the practice, we can also just say that she is part of the practice. In a second, still somewhat preliminary, step, let us remind ourselves that in the present context, we are talking about the sketched score-keeping practice with calibrational parts. As we have seen, in this practice, we always convey fragments of meaning-constituting networks among signs (a means b; don't you mean $p$ by q?; if c falls under $f$, then surely it also

\footnotetext{
${ }^{9}$ I lift this formulation from Kiesselbach (2012).

10 Past communicative success typically suffices for practical purposes (in fact, at the limit, there is nothing else to go by, because all signals - even those used in calibration - are open for interpretation, and for that, we are forced to judge on the basis of finite stretches of past linguistic conduct). Only before this background did my original paper approvingly cite Brandom's default-challenge structure (Brandom 1994, 177; Kiesselbach 2014, 436) when relaxing the assumption that agents always start by explicitly signaling which norms they (are about to) follow.
} 
falls under $g$, etc.) or between signs and salient features of the empirical environment (do you mean this kind of thing by z?, e.g.).

Finally the third step. True: to be taken as making a move within this practice at all, rather than just making a sound (or making a move in a different game), my interpreter must extend to me a particular interpretive stance. In theory, my interpreter can always doubt me - her interpretations are provisional. Indeed, my whole further conduct will be taken, by my interpreter, as a kind of test-case. But if my playing along is stable, rewarding her interpretive charity and vindicating her interpretation, there is a sense in which the circle holds. Within the interpreter's interpretation, I count as bound; and since the practice to which I am bound contains calibration manoeuvres, I count as bound in such a way that I can make moves whose point is to suggest to her how to interpret me - just what rules and thus what practice to take me to be bound to.

This circularity - if we want to call it circularity - is actually complicated by a reciprocity between us: the interpreter is also interpreted; the interpreted agent is also an interpreter. And there is yet another complicating point to note: we as theorists are located within the system of mutual interpretation. Our interpretations of certain agents as having bound themselves (actually bound, we may be tempted to add) are interpretations on a par with those of other agents in the game, and potentially in competition with theirs. ${ }^{11}$

But now, note two things about this circle of interpretations. Firstly, it is compatible with the possibility of break-downs. There is no reason to fear that anything erstwhile participants in the practice do will always appear to conform to the interpretations..$^{12}$ Agents can start to diverge wildly so that the moves within the practice fail to hook onto each other in the appropriate ways and the practice dissolves (as does, by the way, the possibility of talking about meanings). ${ }^{13}$ Secondly, this circular structure is compatible with causal or historical accounts of its emergence, just as the betterknown chicken-egg-circularity is compatible with an evolutionary account of its emergence, and just as the existence of nominal money (which, at least on some theories, also comes about by circular promising) is compatible with historical accounts of its emergence.

\footnotetext{
11 In Kiesselbach (2012), I have focused on yet another dimension of circularity: to make a normative pronouncement, for example a pronouncement about the appropriateness of someone's assessment of someone else, is to display an attitude which contributes to validating the normative pronouncement. I show this with respect to value- and meaning-statements. This is a dimension of the answer to the question what makes assessment appropriate (Reinikainen 2020,5) which, for reasons of space, has not been in the center of this essay.

12 It is also simply not true that "virtually anything can count as an acknowledgment signal within the practice" (Reinikainen 2020, 12).

${ }^{13}$ Note an interesting asymmetry here: breakdowns are evidence that interpretations were faulty; absence of breakdowns is not evidence that interpretations are correct - hence the sense in which all interpretations are provisional.
} 
This, then, is the reason, in general form, for which we do not have to fear the circularity: it is not a problem afflicting an account or explanation, but a feature of a social system - a social system of which we are a part. And if we accept that we, as theorists, may as well describe the system from within, the circularity ceases to be a problem.

Before continuing to the next section, let me recapitulate and emphasize that Reinikainen asks for an account of "consent to a norm" (again: Reinikainen's term) which is general (not depending on a particular norm or practice), capable of forestalling all logically permissible defenses of an allegedly norm-violating agent, and understandable outside of the calibrational practice within which agents mutually assess and, if possible, align each others' conduct. ${ }^{14}$ In the following section, I want to find out why one might spell out such demands.

\section{Humean intuitions as barriers to dialectical convergence}

One motivation to look "behind" anti-normativists' explicit arguments lies in the way in which at least Reinikainen analyzes the self-binding which - as I claimed when laying out my model - an assessed speaker must display in order for it to be appropriate to assess her conduct in a particular way. Although he officially accepts the role of such self-binding as a "logical (or transcendental) condition" (Reinikainen $2020,12)$ of a particular interpretation within an interpretive practice, he goes on to treat it as something which is, in the first place, causally active. It is telling that Reinikainen's first attempt at an analysis of the "consent" is to treat it as a "proattitude", whose capacity to underwrite normativity or prescriptivity he finds less puzzling.

A second reason is that both Kaluziński and Reinikainen display a particular understanding of normativity when they discuss the calibration model's "admission" that agents may have recourse to "excuses" when confronted about apparent normviolations (show that they had been following a different norm all along). On their view, the availability of excuses is something that makes the claim that language use is a normative practice more dubious, not less. Whatever motivates this view, it is certainly not a theoretically neutral agent's stocktaking of her own practice, as such excuses are common, and frequently lead to re-interpretations of speakers invoking them..$^{15}$

It is in these two aspects, I contend, that the attachment to a Humean conception of motivation and action is visible. By Humeanism, I shall mean an implicit or explicit doctrine about the explanation (not justification) of action. I read Hume's dictum that "reason is (and ought to be) the slave of the passions" (Hume, 1978 [1739], II.iii.3,

14 The demand of a standpoint outside of the game of mutual interpretations is also visible, I think, in Kaluziński's paper.

${ }^{15}$ To a theorist who accepts that linguistic practice involves networks of myriads of norms, this is hardly a surprise. 
415) as gesturing towards the doctrine that any full explanation of an action must involve an implicit or explicit reference to a causally effective attitude ("passion", usually understood in a wide way) on the part of the agent.

An attachment to Humeanism is actually admitted by Reinikainen (Reinikainen 2020, 5). Let me give some reasons to think that the connection is not coincidental, and that Humean commitments are in fact an important reason for which normativism about meaning continues to get puzzled looks in large sections of the philosophical community. There are two ways in which Humeanism becomes relevant in the disagreement on the normativism of meaning, one (briefly touched upon in the introduction) which comes out in the interpretation of what "prescriptivity" is; and one deeper one which reaches all the way down to methodological (or metaphilosophical) questions.

Humeanism is not, of course, a theory about whether meaning is normative. For this reason, the doctrine of Humeanism is, strictly speaking, compatible with any view concerning the normativity of meaning. ${ }^{16}$ But Humeanism is a theory dedicated to action explanation, and linguistic manoeuvres surely fall under the concept of action. Like other kinds of actions, linguistic manoeuvres are carried out for reasons. It stands to reason that the meaning of a sign is at least part of a reason to employ the sign in (or as) a linguistic manoeuvre.

Here lies the first tension between Humeanism and normativism about meaning in general. This is nothing new and has been ably spelled out by Glüer and Pagin (1998), but let me briefly mention it. Humeanism insists that reasons, if they are capable of motivating - or "guiding" (Glüer and Pagin) - at all, must include (or combine with) pro-attitudes, and it is not immediately intuitive that there are pro-attitudes directed to meanings as such. This is an obvious problem for the claim that linguistic norms are "prescriptive".

While this is surely a barrier between Humeanism and normativism about meaning, it is not an unsurmountable one. A Humean who wants to hold on to normativism about meaning, and accept the fact that meanings provide reasons, can seek or postulate pro-attitudes directed towards (or being elicited by) meaning itself - proattitudes distinct from prudence, morals, etc. This is perhaps less implausible than it might initially seem, as novel findings in developmental psychology can be read as corroborating the existence of such states. ${ }^{17}$ It is true that on this reading, the normativity of meaning becomes an empirical phenomenon. Normativists - myself included - may have reasons to resist such a reading, but this is some way of making (something like) the normativity of meaning compatible with Humeanism.

But there is a deeper tension between Humeanism and normativism, at least the normativism which surfaces in the calibration account. The point is that the Humean

${ }^{16}$ Assuming that the relevant doctrines are viewed independently, without factoring in typical collateral commitments.

17 See, for example, Paulus and Wörle (2019). 
commitments of anti-normativists emerge not only in the latter's temptation to hypothesize "pro-attitudes", but also in the less obvious theoretical commitments identified in Reinikainen's (and perhaps Kaluziński's) implicit demands on a theory of the normativity of meaning. Since Humeanism takes itself to delineate the contours of acceptable action explanation, and since its main ingredient is the insistence on causal explanation, Humeans demand generality (independence from particular practices or norms), an absence of exceptions which are not built into the theory ("excuses", at the level of the practice), and a location of the theorist outside of the practice about which she makes theoretical (in fact scientific) pronouncements - in other words, a Humean account is a "sideways on" account. These are the commitments I highlighted at the end of the previous section as instances of opposition to the score-keeping account sketched in support of the normativity of meaning thesis.

\section{Ways forward}

So where to go from here? Well, one possible way would be to insist that a defence of the normativity of meaning is, strictly speaking, independent of the issue of how to explain action. Indeed, when a normativist - and certainly someone who finds my strategy of defending the normativity of meaning plausible - speaks of reasons to speak in particular ways (moreover: reasons which are not reasons of morality or prudence), she is not in the business of explaining action. Rather, she is in the business of elucidating a region of everyday linguistic practice and its distinctive rules. In this business, one could justifiably insist, the demands for generality, absence of exceptions and an external perspective are simply out of place, as would be the expectation that in elucidating our ordinary linguistic manoeuvres, the theorist must offer some causal story of the scores (normative statuses) within the game.

In principle, a Humean might accept this rejoinder, clearing the way to her accepting my account of the calibration practice - and the normativity of meaning thesis it is meant to support. There would still be the worry that on a Humean conception of reasons, semantic reasons are only dubiously connected with motivation and could not "guide" by themselves. As indicated above, in light of psychological findings which seem to support the existence of a deep-rooted motivation to adhere to (and enforce) semantic normativity, this may not necessarily be a deal-breaker.

At the same time, this reaction is probably not too likely, because for many Humeans, the principal attraction of Humeanism is its promise to dissolve philosophical puzzlement not through elucidation of everyday discourse, but by reference to a causal and hence quasi-scientific story.

This, then, would favor the other way of dealing with the tension: to shift the debate into the arena of action-explanation, where the Humean programme can be explicitly and generally addressed. 
In closing, let me suggest two ways in which the matters discussed in this short article may influence that debate: Firstly, the picture of linguistic norms and their expression and institution in calibration practices can contribute to the balance of considerations against Humeanism. Secondly, even if a philosopher with Humean commitments is not swayed to give up Humeanism, the account offered here still has a component that could make it - and thus normativity of meaning in general - more palatable to her than she may initially have thought, prompting her to find exceptions to Humeanism's broad requirements on philosophical theories.

Let me spell these two points out in some more detail. Firstly, the calibration account coheres best with an understanding of reasons ${ }^{18}$ which is generalizable beyond the context of meaning, and successful at ("phenomenologically") capturing the practice of invoking reasons. On this understanding, reasons do not have a close relationship with pro-attitudes of any sort. According to it, we call something a reason, because, among other things, it normally ${ }^{19}$ motivates - that is its grammatical function. And everyday practice knows plenty of cases in which we are motivated to do something even though we lack any independently recognizable pro-attitudes. We are motivated because we recognize the reason, because being motivated by it is the natural case for us in the practices which make us who we are. Without the generally elicited motivation, the practice would simply not have evolved in the form that it has. Since this understanding is phenomenologically plausible, it just may break the spell which pulls philosophers towards Humeanism, namely the puzzled question "what else if not a pro-attitude can motivate and hence be a reason?".

The plausibility of the sketched picture's account of reasons (generally) and meanings (in the context of language) also speaks against philosophical accounts which do not take (or which reject the intelligibility of) the participant perspective quite generally. Once one accepts that reasons and meanings are essentially for participants of the relevant practice, "sideways-on" accounts of such statuses lose their attraction.

Secondly, the practice-calibration account of reasons contains an element which may make the whole account more palatable to Humeans than one might think. The point is that the account, although it is not "object-naturalistic", is "subject-naturalistic" (Huw Price 2004). It is compatible with an account in non-normative (naturalistically acceptable) language of what an agent must do in order for her statements to be meaning-statements and hence normative. The strategies an agent carries out within the calibration practice can be described in non-normative terms - she compares her dispositions to those of her peers; in case of differences, she either attempts to adapt to those of her peers or issues a signal intended to get her peers to adapt, etc. pp. and yet, her meaning statements are seen to be irreducible into non-normative language.

\footnotetext{
${ }^{18}$ I should perhaps stress that "reasons", here, refer to pro-tanto reasons. See Glock $(2019,312)$.

19 This is an important qualification. The exception is akrasia, a breakdown of rationality which no theory should rule out.
} 
They are essentially prescriptive, and they are essentially bound up in the circular structure described above. ${ }^{20}$

This, then, may move Humeans to find ways of making their commitment to naturalistic explanations in philosophy compatible with the kind of elucidation of linguistic practice sketched here in defence of the normativity of meaning thesis.

At any rate, if the diagnosis presented in this paper is on the right track, participants to the debate on the normativity of meaning may have to devote some thought on its relationship to the question on how to explain action.

\section{References}

Brandom, R. 1994. Making It Explicit. Cambridge Mass.: Harvard University Press.

Enfield, N.J. and Sidnell, J. 2019. "The Normative Nature of Language". In: The Normative Animal? On the Anthropological Significance of Social, Moral, and Linguistic Norms, edited by N. Roughley and K. Bayertz. 265-278. Oxford: Oxford University Press.

Glock, H. 2019. "The Normativity of Meaning Revisited." In: The Normative Animal? On the Anthropological Significance of Social, Moral, and Linguistic Norms, edited by N. Roughley and K. Bayertz. 295-320. Oxford: Oxford University Press.

Glüer, K. 1999. "Sense and Prescriptivity." Acta Analytica 23 (14): 111-128.

Glüer, K., and P. Pagin. 1998. "Rules of Meaning and Practical Reasoning." Synthese 117 (2): 207-227.

Hattiangadi, A. 2006. “Is Meaning Normative?” Mind 21 (2): 220-240.

Hume, D. [1739] 1978. A Treatise of Human Nature, ed. L. A. Selby-Bigge and P. H. Nidditch. Oxford: Clarendon.

Jackman, H. 2005. "Temporal Externalism, Deference and Our Ordinary Linguistic Practice." Pacific Pbilosophical Quarterly, 86 (3): 379-394.

Kaluziński, B. 2016. "Assessment, Scorekeeping and the Normativity of Meaning: A Reply to Kiesselbach.” Acta Analytica 31 (1): 107-115.

Kiesselbach, M. 2012. "Constructing Commitment: Brandom's Pragmatist Take on Rule-Following.” Philosophical Investigations 35 (2): 101-126.

Kiesselbach, M. 2014. "The Normativity of Meaning: From Constitutive Norms to Prescriptions." Acta Analytica 29 (4): 427-440.

Kompa, N. 2019. "Language Evolution and Linguistic Norms." In: The Normative Animal? On the Antbropological Significance of Social, Moral, and Linguistic Norms, edited by N. Roughley and K. Bayertz. 245-264. Oxford: Oxford University Press.

${ }^{20}$ For details, see Kiesselbach (2012). 
Lewis, D. 1979. "Scorekeeping in a Language Game." Journal of Philosophical Logic 8(1): 339-359.

Paulus, M., and M. Wörle. 2019. "Young Children Protest against the Incorrect Use of Novel Words: Toward a Normative Pragmatic Account on Language Acquisition." Journal of Experimental Child Psychology 180: 113-122.

Price, H. 2004. "Naturalism without Representationalism." In Naturalism in Question, edited by M. De Caro and D. MacArthur. 71-88. Cambridge Mass.: Harvard University Press.

Reinikainen, J. 2020. "Meaning Still Not Normative: On Assessment and Guidance." International Journal of Philosophical Studies 1-17.

Sellars, W. 1954. "Some Reflections on Language Games." Philosophy of Science 21(3): 204-228. doi:10.1086/287344. 